\title{
La gobernanza híbrida neoliberal en la educación pública
}

\author{
Enrique-Javier Díez-Gutiérrez 이 @ \\ Universidad de León (ULe), España
}

Resumen. En este texto revisamos las tendencias actuales en las políticas de gobernanza de los sistemas educativos, analizando el caso de España con sus últimas leyes educativas. Políticas que importan y aplican ideas y prácticas del sector empresarial al sector público educativo, con la colaboración de nuevos actores privados y con la finalidad de que las escuelas se gestionen cada vez más como empresas. Este enfoque se conoce como "gobernanza neoliberal". Este gerencialismo neoliberal se impulsa a través de tres estrategias indirectos de "soft power": los principios de la elección y la competición, los estándares de rendimientos y los sistemas de rendición de cuentas, donde la función del Estado sería la supervisión de los resultados, dejando a los actores que actúen de forma autónoma. Estas tecnologías de control y gestión sirven para "gobernar sin gobierno", invitando a someterse por sí mismas a los profesionales de la educación y las comunidades educativas, que aprenden así a gobernarse siguiendo ciertas normas y creencias establecidas a distancia, que se van arraigando profundamente. Se presentan como elementos de eficiencia, neutrales y técnicos. Se está así generando políticas "interiores" que construyen un tipo de subjetividad y de identidad, (re)socializando en principios, prácticas y valores neoliberales.

Palabras clave: nueva gestión pública; gobernanza neoliberal; gobernar sin gobierno; gobernanza híbrida.

\section{A governança híbrida neoliberal na educação pública}

Resumo. Neste texto revisamos as tendências atuais nas políticas de governança dos sistemas educacionais, analisando o caso da Espanha a partir das últimas leis de Educação. Políticas que importam e aplicam ideias e práticas do setor empresarial na rede pública de Educação, com a colaboração de novos atores privados, visando que as escolas sejam administradas cada vez mais como empresas. Este enfoque é conhecido como "governança neoliberal". Este gerencialismo neoliberal é impulsionado por três estratégias indiretas de "soft power": os princípios da eleição e da competição, os padrões de rendimentos e dos sistemas de prestação de contas, onde a função do Estado é supervisionar os resultados, deixando os atores agirem de forma autônoma. Estas tecnologias de controle e gestão servem para "governar sem governo", convidando os profissionais da educação e as comunidades educativas a se submeterem a si mesmos, aprendendo desta maneira a se governarem seguindo certas normas e crenças estabelecidas a distância, que vão se arraigando profundamente. São apresentadas como elementos de eficiência, neutros e técnicos. Assim estão sendo geradas políticas "interiores" que constroem um tipo de subjetividade e de identidade, (res)socializando em princípios, práticas e valores neoliberais.

Palavras-chave: nova gestão pública, governança neoliberal, governar sem governo, governança híbrida.

\section{Neoliberal hybrid governance in public education}

Abstract. In this paper I review the current trends in the governance policies of education systems, analyzing the case of Spain with its latest educational laws. Policies that import and apply ideas and practices from the business sector to the public education sector, with the collaboration of new private actors and with the aim that schools are increasingly managed as businesses. This approach is known as "neoliberal governance." This neo-liberal management is driven through three indirect "soft power" strategies: the principles of choice and competition, performance standards and accountability systems, where the function of the State would be to monitor the results, leaving the actors to act autonomously. These control and management technologies serve to "govern without government," inviting themselves to submit themselves to education professionals and educational communities, who thus learn to govern themselves by following certain norms and beliefs established at a distance, which are deeply rooted. They are presented as efficiency, neutral and technical elements. It is thus generating "internal" policies that build a type of subjectivity and identity, (re) socializing in neoliberal principles, practices and values.

Keywords: new public management, neoliberal governance, govern without government, hybrid governance. 


\section{Introducción}

La economía neoliberal se está asumiendo progresivamente como modelo de gobernanza y gestión de la educación pública. Se trata de "aplicar" ideas, métodos y prácticas del sector industrial a fin de hacer que el sistema educativo funcione de una forma "crecientemente comercial" y se gestione cada vez más como una empresa (Ball y Youdell, 2007).

Para ello se ha construido un discurso tecnocrático, aparentemente despolitizado, que se nos presenta como algo inevitable y necesario para "modernizar" el sistema educativo. Su naturaleza política queda encubierta, al poner en manos de "expertos" y tecnócratas las decisiones de cómo gestionar lo público, como si esas decisiones fueran técnicas o "asépticas" y no obedecieran a principios e ideologías.

Este nuevo paradigma de la práctica organizativa es lo que se conoce como "gobernanza híbrida neoliberal", introduciendo en esta nueva gestión compartida a los nuevos "filántropos", que operan en una esfera parapolítica, en la que pueden desarrollar también su propia y personal agenda política. De esta forma, gestión tecnocrática y filantropocapitalismo (Saura, 2017) maniobran juntos para reemplazar los procesos democráticos del sistema educativo. Son los nuevos actores de la gobernanza que participan de forma activa y que dan paso a este nuevo discurso de la gobernanza neoliberal (Ball, 2016).

Este gerencialismo neoliberal pretende la creación de mercados en educación impulsados por los principios de la elección y la competición, los estándares de rendimientos y los sistemas de rendición de cuentas. La única función del Estado sería la supervisión de los resultados, dejando a los actores que actúen de forma autónoma (Moya, 2014).

El nuevo sistema de gestión opera a través de tres grandes estrategias de "soft power", mediante elementos indirectos de gobierno: el primero, la "privatización soft" a través de la irrupción de consorcios privados, fundaciones empresariales, partenariados, etc. que aseguran "apoyar" los procesos educativos; el segundo, el denominado "gobierno a distancia", que encuadra los resultados exigidos y por tanto las prioridades educativas, a través de mecanismos como las evaluaciones estandarizadas, la rendición de cuentas o los rankings; y, por último, la introducción en el discurso de gestión del binomio "libertad-responsabilidad" referida a la "autonomía" de los centros y comunidades educativas, pero infradotada de recursos y medios, creando las circunstancias para que "actúen correctamente" de manera "libre y autónoma", asumiendo que son los únicos responsables de los resultados obtenidos (Collet y Tort, 2016). 
Este enfoque de gubernamentalidad foucaultiana, de "gobierno-porla-mente" (Foucault, 1975), supone aprender a "gobernarse por sí mismo". Ya no requiere gobiernos externos, puesto que, efectivamente, invita a someterse por sí mismas a las personas, las comunidades educativas y los centros, que aprenden así a gobernarse siguiendo ciertas normas establecidas a distancia que se van arraigando profundamente.

Todas estas tecnologías de control y gestión sirven para "gobernar sin gobierno". Se presentan como elementos de eficiencia técnica, neutrales y técnicos, en vez de como opciones ideológicas y políticas. Lo que importa en esta nueva gestión educativa de corte neoliberal, no es la legitimidad de partida, basada en valores y principios, sino la legitimidad de salida, basada en los resultados obtenidos (Ball, 2016). Eficacia, eficiencia, mínimo costo, corto plazo, competencia, es la nueva "lógica" que va penetrando, siendo vivida y practicada, compartida y proclamada de manera creciente, como la nueva "normalidad" (Collet y Tort, 2016). Quien no los practica queda excluido o es tratado como "disidente"; quien los practica y no obtiene "éxito", debe asumir que el único culpable es él.

\section{Nueva Gestión Pública (NGP) en la educación}

El sector neoliberal, que tiene una fe inquebrantable en la libre regulación del mercado y la desaparición del Estado (excepto cuando les tiene que rescatar), está imponiendo este modelo de gestión. De forma cada vez más omnipresente, aparece en numerosos informes de los Organismos Internacionales (BM, FMI, OCDE), pasando de ser "recomendaciones", a la hora de formular políticas educativas, a prescripciones, prácticamente insoslayables, para los gobiernos de todo el mundo (Moreno-Hidalgo y Manso, 2017).

Creen firmemente en su propio dogma: la gestión privada, que estimula la iniciativa espoleada por el lucro y la ganancia individual, gestiona mejor y de forma más eficiente los centros educativos y universitarios, que la gestión pública y común de los bienes y derechos colectivos.

La Nueva Gestión Pública (NGP), ha surgido como un programa de reforma del sector público, que aplica conocimientos e instrumentos de la gestión empresarial, con el fin supuestamente de mejorar la eficacia y la eficiencia del rendimiento de los servicios públicos, promoviendo su calidad. Sin embargo, hay ingente literatura académica que desmiente la idea de los valiosos efectos de estos modelos (Verger y Bonal, 2012), confirmando sus efectos nocivos y radicalmente desfavorables en las organizaciones con fines sociales, como las educativas. 
De todos los aspectos que son inequívocamente señalados como adversos (Bernal y Lacruz, 2012; Fernández-González, 2016; Saura y Muñoz, 2016), como recortes presupuestarios, privatización, separación de producción y provisión, subsidiariedad de lo público, externalización, auditoría estandarizada en función de resultados, pago por resultados, concepto de cliente, competitividad, gestión contable de personal, re-pago del usuario, competencia y uso burocrático de las tecnologías de la información, se pueden destacar algunos aspectos: a) el mantra retórico, profusamente difundido, de "hacer más con menos"; b) la implantación en la gestión pública de las técnicas de gestión y dirección, siguiendo el modelo jerárquico de empresa del sector privado; c) la autonomía financiera, traducida en recortes de financiación, de los centros educativos d) la externalización de todos los servicios posibles, convertidos en negocios, a empresas privadas subsidiarias; e) la rendición de cuentas mediante evaluaciones estandarizadas que faciliten ránquines; f) la promoción "comercial" de la preferencia de selección en función de los ránquines; g) el pago por resultados o el supuesto estímulo de los incentivos.

Las características de su aplicación en educación, y más en concreto en España, especialmente tras la aplicación de la LOMCE (Bernal y Vázquez, 2013), podríamos sintetizarlas en el siguiente cuadro gráfico, que resume buena parte de las críticas que las investigaciones y estudios destacan:

\begin{tabular}{|c|c|c|}
\hline Características & Implicaciones en educación & Aplicación en España \\
\hline $\begin{array}{l}\text { "Hacer más con } \\
\text { menos" }\end{array}$ & $\begin{array}{l}\text { Recortes, precarización de las con- } \\
\text { diciones laborales del profesorado, } \\
\text { aumento horas docentes y más } \\
\text { estudiantes por aula, despidos, } \\
\text { merma retributiva; menos becas y } \\
\text { más tasas en etapas no obligatorias } \\
\text { y en servicios como el comedor o el } \\
\text { transporte escolar. }\end{array}$ & $\begin{array}{l}\text { Se han recortado } 9.000 \text { millones de } \\
\text { euros en educación desde } 2008 \text {. Pero } \\
\text { los compromisos del Gobierno del PP } \\
\text { con la UE recortarán aún más, redu- } \\
\text { ciendo la inversión pública educativa } \\
\text { al 3,9\% del PIB, dejando a España a } \\
\text { la cola de la UE y la OCDE (la media } \\
\text { en la UE es del } 6,2 \% \text { ). }\end{array}$ \\
\hline $\begin{array}{l}\text { Subsidiariedad de } \\
\text { lo público }\end{array}$ & $\begin{array}{l}\text { Lo público cubrirá las necesidades } \\
\text { allá donde no es rentable para la } \\
\text { iniciativa privada (norma: Directiva } \\
\text { Bolkenstein y Tratado de la Consti- } \\
\text { tución Europea). Lo público ha de } \\
\text { retirarse donde llegue la iniciativa } \\
\text { privada. }\end{array}$ & $\begin{array}{l}\text { LOMCE: la programación de la edu- } \\
\text { cación obligatoria tendrá en cuenta la } \\
\text { oferta de centros privados concertados } \\
\text { existente, además de garantizar plazas } \\
\text { que pueden ser concertadas por la } \\
\text { demanda social. }\end{array}$ \\
\hline
\end{tabular}

Incorporación al sector público de LOMCE: Organización jerárquica y técnicas de gestión y dirección Gerencialismo. La dirección se con-

Gerencia y administración "eficiente" de empresa del sector privado. Se vierte en una función unipersonal y potencia la "profesionalización" de no colegiada, pasando también a la dirección escolar como gerente, tener el control en la "gestión de experto en gestión económica, personal". Una dirección nombrada empresarial y de recursos humanos. por la administración gobernante, afín a la misma. 


\begin{tabular}{|c|c|c|}
\hline Características & Implicaciones en educación & Aplicación en España \\
\hline $\begin{array}{l}\text { Organización } \\
\text { "eficaz" }\end{array}$ & $\begin{array}{l}\text { Se produce un trasvase de compe- } \\
\text { tencias desde el Consejo Escolar } \\
\text { hacia el director ,quitando a las } \\
\text { comunidades educativas la capaci- } \\
\text { dad de participar en el gobierno y } \\
\text { evaluación de los centros. }\end{array}$ & $\begin{array}{l}\text { LOMCE: El consejo escolar queda } \\
\text { relegado a funciones meramente } \\
\text { consultivas y no decisorias. El di- } \\
\text { rector ordena y manda. Eliminación } \\
\text { del funcionamiento democrático y } \\
\text { participativo. }\end{array}$ \\
\hline Externalización & $\begin{array}{l}\text { Externalización de la mayoría de } \\
\text { los servicios educativos. Además de } \\
\text { los habituales, comedor, transporte, } \\
\text { etc., algunos países también lo han } \\
\text { hecho con la inspección, la forma- } \\
\text { ción del profesorado, etc. }\end{array}$ & $\begin{array}{l}\text { Se confiere a los directores o las di- } \\
\text { rectoras la capacidad para contratar } \\
\text { con terceros, actividades vinculadas } \\
\text { a programas. La contratación de } \\
\text { profesorado de habla inglesa sin } \\
\text { oposición, etc. }\end{array}$ \\
\hline $\begin{array}{l}\text { Rendición de cuen- } \\
\text { tas y accountability }\end{array}$ & $\begin{array}{l}\text { Estándares de medición en función } \\
\text { de resultados, expresados en térmi- } \\
\text { nos cuantitativos. Rankings }\end{array}$ & $\begin{array}{l}\text { LOMCE: Evaluaciones y reválidas } \\
\text { estandarizadas. }\end{array}$ \\
\hline $\begin{array}{l}\text { Autonomía y pago } \\
\text { por resultados }\end{array}$ & $\begin{array}{l}\text { Se aplican incentivos a los centros, } \\
\text { no ya en función de las necesidades } \\
\text { de su alumnado, sino de acuerdo } \\
\text { con el puesto en el ranking. Ley del } \\
\text { mercado. Aquellos 'productos' más } \\
\text { demandados serán los que haya } \\
\text { que reforzar. }\end{array}$ & $\begin{array}{l}\text { LOMCE: liga autonomía escolar a } \\
\text { especialización competitiva de los } \\
\text { centros y a los resultados académicos } \\
\text { en función de los cuales llegarán } \\
\text { recursos diferenciados }\end{array}$ \\
\hline Competitividad & $\begin{array}{l}\text { Competitividad entre centros, anun- } \\
\text { ciando en el mercado de consumo } \\
\text { su especialidad y sus logros }\end{array}$ & $\begin{array}{l}\text { LOMCE: establecerá rankings que } \\
\text { se publicitarán como si una liga de } \\
\text { futbol se tratara }\end{array}$ \\
\hline $\begin{array}{l}\text { Elección del } \\
\text { cliente }\end{array}$ & $\begin{array}{l}\text { Considerado como cliente que exige } \\
\text { resultados ante su inversión entre las } \\
\text { posibles ofertas clasificadas en un } \\
\text { "mercado libre". }\end{array}$ & $\begin{array}{l}\text { LOMCE: los "clientes" podrán com- } \\
\text { parar en el ranking y elegir aquél que } \\
\text { más ventajas competitivas les aportea } \\
\text { su prole en el futuro mercado laboral }\end{array}$ \\
\hline Cobro al usuario & $\begin{array}{l}\text { Introducción de estrategias de re- } \\
\text { pago, concibiendo la educación ya } \\
\text { no como derecho que el Estado ha de } \\
\text { garantizar vía impuestos, sino como } \\
\text { oportunidad de inversión a futuro. }\end{array}$ & $\begin{array}{l}\text { Tasas de matrículas universitarias } \\
\text { han subido hasta un } 66 \% \text { en alguna } \\
\text { CCAA, pudiendo llegar a un } 362 \% \\
\text { la } 2^{\mathrm{a}}, 3^{\mathrm{a}} \text { y } 4^{\mathrm{a}} \text { matrícula. Las becas se } \\
\text { han reducido y los másteres triplican } \\
\text { su precio. }\end{array}$ \\
\hline $\begin{array}{l}\text { Gestión de per- } \\
\text { sonal }\end{array}$ & $\begin{array}{l}\text { Secuestionan los procedimientos de } \\
\text { gestión del personal basados en una } \\
\text { selección transparente, en función } \\
\text { del mérito e igualdad. Se conforman } \\
\text { las plantillas docentes de acuerdo a } \\
\text { laadecuación al proyecto del director } \\
\text { nombrado por la administración. }\end{array}$ & $\begin{array}{l}\text { LOMCE: la dirección podráseleccionar } \\
\text { al profesorado, "estableciendo los } \\
\text { requisitos y méritos para los puestos } \\
\text { de personal funcionario docente" y } \\
\text { "podrárechazar interinos procedentes } \\
\text { de las listas". }\end{array}$ \\
\hline Descentralización & $\begin{array}{l}\text { Descentralización financiera de } \\
\text { centros en base a un presupuesto } \\
\text { propio, estableciendo que no forman } \\
\text { ya parte de un "todo" que es el siste- } \\
\text { ma educativo, sino que cada uno se } \\
\text { convierte en una entidad individual } \\
\text { que debe entrar a competir con los } \\
\text { demásy debeademás rentabilizarsus } \\
\text { recursos (como si fuera una empresa) }\end{array}$ & $\begin{array}{l}\text { Se centraliza el control pedagógico (a } \\
\text { nivel curricular, de evaluación del sis- } \\
\text { tema y de formación de los docentes), } \\
\text { pero alentando la búsqueda de fuentes } \\
\text { de financiación privada alternativas, } \\
\text { así como patrocinadores y mecenas, } \\
\text { dada la falta de recursos públicos, ante } \\
\text { los recortes presupuestarios. }\end{array}$ \\
\hline
\end{tabular}




\section{La gestión eficaz de la "calidad" educativa}

La gestión de la calidad proviene de un enfoque, desarrollado a mediados del siglo pasado, que ponía el énfasis en la mejora continua de los procesos dentro de las organizaciones. Este movimiento, que se inició en el mundo de la empresa, logró afianzarse en la gestión empresarial entre los años cincuenta y ochenta, con medidas de cuantificación y categorías estandarizadas orientadas a la satisfacción del "cliente" (Bautista, 2012).

Dado que la mayoría de empresas que acogieron esos planteamientos eran burocráticas, es decir que consideraban que era clave tener normas y reglas claras sobre cómo hacerlo todo en las organizaciones, o estaban centradas en el logro, la competitividad y la fijación de objetivos y estrategias, su implantación se llevó a cabo desde de este enfoque. Lo cual supuso que la gestión de la calidad se transformó en normas y auditorías de calidad.

El problema es que este sistema no solo genera inflexibilidad, extendiendo poco a poco la necesidad de fijar objetivos, metas, indicadores, acciones de mejora, estrategias, sino que introduce además la sospecha sobre los profesionales de la educación y, por tanto, la necesidad de controlar y vigilar a las personas o grupos, teniendo éstos que demostrar continuamente que han realizado las actividades establecidas y han sido verificadas y ratificadas adecuadamente por la administración educativa. Todo ello impide la autonomía y centrarnos realmente en cómo hacemos nuestro trabajo y cómo lo mejoramos; es decir, acaba importando más la cantidad (Chiva, 2017), y el cumplimiento de los estándares establecidos en la auditoría de calidad que la calidad de lo que se hace, paradójicamente.

Pero la gestión eficaz de la calidad ha ido más allá aún. La doctrina del mercado escolar ha introducido un nuevo componente ligado a la eficacia, basada ésta en el análisis de la relación costes-beneficios. Además de la fijación de estándares e incentivos, de la verificación y el control, este modelo exige la constante presentación de pruebas también de rentabilidad económica de las acciones emprendidas.

Este modelo está alejado de los planteamientos pedagógicos. Al sobrevalorar lo que es visible y lo que es cuantificable, el modelo del mercado va exactamente contra la lógica pedagógica que exige tiempo. El mercado funciona a corto plazo y las soluciones a las que conduce son superficiales, mientras que las soluciones a numerosos problemas educativos reclaman decisiones que operen a largo plazo (Aróstegui y Martínez, 2008). 
En estas condiciones la educación se convierte en un artículo comercial cuyos resultados deben ser reducibles a unos 'indicadores de rendimiento normalizados' en función de esa supuesta eficacia.

La concepción de la eficacia, que se ha ido imponiendo progresivamente en la educación, considera que ésta es siempre medible, a través de métodos y técnicas estandarizadas y reproducibles a gran escala. Esta concepción exige la comparación de resultados de la actividad pedagógica. Los resultados cuantificados se presentan como un criterio de calidad de las diferentes escuelas y como la medida del nivel educativo escolar.

La dificultad estriba en que creer que la eficacia y la calidad de la educación es representable mediante estándares, medibles por test, constituye una visión reduccionista -en parte herencia del positivismo y en parte de la cultura de la eficiencia y la competitividad ligada al mundo empresarial-que no toma en cuenta que ninguna medida o cuantificación exacta puede reflejar procesos sociales o individuales complejos como el aprendizaje.

Este sistema persigue el progresivo aumento de la mercantilización de la educación, ofreciendo los mecanismos de comparación que necesitan los "consumidores y consumidoras" para hacer que los mercados funcionen como tales, eligiendo entre las "ofertas más competitivas" en estos parámetros. Por eso estas políticas presionan a las escuelas para que muestren sus resultados en rankings al público consumidor (como los accionistas presionan para cotizar en bolsa), y amenazan a las escuelas que no muestren un aumento constante de resultados con retirarles la financiación o con la pérdida del control y entregar su gestión a empresas privadas.

La filosofía de la calidad, importada del mundo empresarial, aporta al mundo educativo un vocabulario diferente. Los términos de eficacia, eficiencia, rendimiento, productividad, competitividad, calidad..., han reemplazado a los de igualdad de oportunidades o emancipación (Colella y Díaz, 2017). En el fondo, la preocupación básica radica en "obtener resultados" medibles y escalar en el ranking, de tal forma que el centro sea más atractivo y demandado frente al resto de "ofertas", en una lucha despiadada y competitiva por atraer más clientes y recibir financiación en función de ello. En esta concepción de la escuela como empresa, saben que una oferta educativa tiene razón de ser si se consigue que haya familias que la "demandan". La demanda se ha convertido en el término talismán, para generar este mercado educativo. 
Esto orienta la política educativa al campo económico más que al pedagógico. El horizonte de los fines de la educación se reduce a la cuantificación de los resultados en los exámenes estandarizados del número de diplomados y tituladas, a su vez relacionados con las inversiones realizadas y las necesidades en mano de obra de la gran industria.

En definitiva, la eficacia y la calidad, hoy asumidas en la ideología educativa neoliberal, encubren unos intereses esencialmente políticos al convertirse en un instrumento sutil para hacer más eficientes y aceptables las prescripciones oficiales determinadas desde los niveles de poder central, pasando desde las formas tradicionales de control burocrático, hacia técnicas de control ideológico.

Este discurso funciona, además, como un discurso moral, que apela a la responsabilidad de las propias comunidades educativas, culpabilizándolas de su crisis o fracaso e induciéndolas a que sean más productivas y rentables. Al mismo tiempo, oculta y desplaza los problemas centrales de la educación, particularmente los vinculados a la financiación de la educación, a problemas de eficacia y eficiencia del sistema educativo. De este modo, la cuestión ya no es de contar con mejores centros, con edificios decentes, bien dotados de todo el profesorado y del apoyo necesario; la calidad depende ahora del 20 funcionamiento del propio centro y de su capacidad para ganarse clientes. La lógica económica se sobrepone a la lógica educativa (Bolívar, 1999).

\section{La Mcdonalización de la escuela}

El modelo económico neoliberal propone que los centros públicos aprendan a gestionarse como lo hacen los privados, que se presentan como modelo de excelencia. Ritzer (1993) y Gentili (1997) denominan a este proceso Mcdonalización, la gestión de la escuela al estilo McDonald's.

Si ya no se pueden aumentar los recursos a causa del recorte de los gastos públicos y la reducción de los impuestos a las grandes fortunas o su desvío para rescatar a los bancos y financieras, el esfuerzo prioritario debe dirigirse hacia la administración "racional" de los sistemas escolares pasando, de las formas de organización democrática y participativa, con el concurso y la implicación de la comunidad educativa, a las formas de organización fundadas en el "gerencialismo" al estilo de las plantas industriales de fabricación. Se pone en marcha un verdadero culto a la eficacia y al rendimiento. 
Para ello se cambia el paradigma de entendimiento de la organización educativa, desviando el protagonismo de la comunidad educativa a los directores y directoras "eficaces", profesionalizando su función y orientándola hacia un modelo de gerencia, de gestión económica, empresarial y de recursos humanos. La participación es sustituida por la organización jerárquica y piramidal. Se pone al frente de las instituciones educativas a verdaderos gestores encargados de aplicar eficazmente las políticas anunciadas como "de modernización", capaces de disciplinar y controlar a los docentes y al alumnado en la base. Es decir, un modelo basado en "la mucha vigilancia y la poca confianza".

Este modelo jerárquico y piramidal de decisión, no potencia una dinámica participativa dentro del centro, sino que, por el contrario, genera un clima desmotivador, burocrático y autoritario, que destruye la confianza y la cooperación colectiva, justamente lo contrario que recomiendan todas las investigaciones sobre liderazgo y organización educativa (Bolívar, 2010, 2013; Bolívar, López y Murillo, 2013; García, 2016; Navarro, Guzmán y Guaderrama, 2016; Sebastián et al., 2016; Vargas, 2017; González, 2017). Como estos autores y autoras han demostrado, parece claro que los modelos verticales, autoritarios y burocráticos han evidenciado ser inservibles en educación, incluso en lo que a la mejora de los aprendizajes se refiere.

Sin embargo, la legislación educativa española, a través de la LOMCE, eliminó la poca democracia que quedaba en los centros escolares, reduciendo al Consejo Escolar a un órgano meramente consultivo y poniendo al frente de las instituciones educativas a verdaderos gestores "afines", encargados de aplicar eficazmente las políticas decididas desde arriba.

Si antes el equipo directivo de un centro era el representante de la comunidad educativa ante la Administración, defendiendo los intereses de la misma y exigiendo el cumplimiento del derecho a la educación por parte de la Administración, ahora los papeles se invierten. Ya con la ley de educación socialdemócrata española (LOE), la dirección se había establecido como representante doble, de la Administración y el centro, avanzando en el modelo de gestores nombrados por la Administración, ejecutores de sus disposiciones, mandos intermedios de esta nueva estructura jerárquica (Viñao, 2016). Pero con la LOMCE el modelo de dirección se radicalizó, convirtiéndose en una función unipersonal y no colegiada, pasando a tener el control de la "gestión de personal" en los centros especializados donde puede llegar a seleccionar al profesorado. Esto, lógicamente, implica crear una burocracia cercana y dependiente de la Administración política de turno, con un "talante más comprensivo" ante sus medidas, difusora y controladora 
de sus instrucciones y afín a su ideología. Se refuerza así el conformismo y la obediencia esperada de los cargos directivos más que incitarlos a confiar en las iniciativas de la comunidad educativa.

La institución escolar ha experimentado una verdadera "transferencia terminológica", una inflación galopante del léxico de la gestión proveniente directamente del mundo de la empresa: "calidad total", "sociedad del conocimiento", “cliente", “marketing", “competencia", “empleabilidad", “flexibilización”, “excelencia”, etc. (Díez y Guamán, 2013).

Incluso la formación para el acceso a la dirección o la que se imparte a los directores y directoras en función, ya no sólo incorpora nociones y visiones del mundo de la empresa (gestión, competencias, balance, calidad total, eficacia...), sino que enseña a leer los problemas que se plantean en el sistema educativo a través de las lentes de la empresa privada. El efecto de este tipo de formación consiste en hacer de la empresa la norma ideal a la que debe plegarse la escuela, y de la dirección, gerentes profesionales y especializados, que cada vez tienen menos que ver con la pedagogía o la educación y más con la economía y la producción. Esto está implicando la consolidación de una "cultura común" de la dirección, gracias a una formación semejante y a referencias similares en quienes se van incorporando a estos cargos. Este tipo de cultura redefine los aprendizajes desde un marco de rentabilidad, tanto en la dinámica del profesorado como del alumnado, impactando no solo en su quehacer sino en su identidad y en las relaciones interpersonales (Ball, 2003).

En definitiva, la NGP erosiona e incluso destruye el apoyo mutuo, la colaboración y el diálogo entre la comunidad educativa, elementos que, según todas las evidencias de la literatura científica y pedagógica, promueven un entorno que favorece tanto el propio desarrollo profesional del profesorado como el aprendizaje de sus estudiantes (Moreno-Hidalgo y Manso, 2017; Verger, Bonal y Zancajo, 2016), generando buen clima y cooperación entre el profesorado y la comunidad educativa, y equipos docentes y organizaciones que aprenden y pueden mejorar, así como sostener tales mejoras a lo largo del tiempo.

\section{La trampa de la "autonomía" gerencial}

Este proceso viene acompañado por un discurso que proclama la necesaria descentralización y autonomía (Quiroga, 2017). Pero no se refiere a una autonomía ligada a la posibilidad de innovación pedagógica de cada centro, a la adaptación del proceso de aprendizaje y enseñanza a los ritmos 
diferentes del alumnado específico de cada centro concreto; a un instrumento, en manos del profesorado y de la comunidad educativa de cada centro, para poder aplicar las estrategias pedagógicas y organizativas más convenientes y adaptadas a la diversidad del alumnado. Aróstegui y Martínez (2008) se preguntan: qué autonomía se pretende realmente cuando no se tiene ni siquiera capacidad para poder pronunciarse respecto al tamaño de los centros y de las aulas, o al sistema de calificación y los estándares establecidos al efecto 0 a reemplazar contenidos curriculares por otros más sensibles a otras expresiones culturales.

El enfoque neoliberal maneja los términos descentralización y autonomía escolar de forma ambigua y calculada, para introducir tras estos significantes con carga positiva, significados radicalmente diferentes. Porque lo que las escuelas se ven obligadas a asumir según la ideología neoliberal es una 'autonomía' presupuestaria en la que no vienen asegurados recursos económicos y humanos. La finalidad es presionar a cada escuela para que busque las vías de cara a limitar sus gastos cada vez más, en un contexto de radical recorte presupuestario, y a buscar otras fuentes de financiación privada y externa.

De hecho, durante la década de los noventa, las reformas educativas que se desarrollaron en EE.UU., Reino Unido, Canadá, Australia, Latinoamérica, enfatizaban discursos que remarcaban términos de elección, responsabilidad, eficiencia y descentralización, ligados a una exigencia de mayor autonomía de funcionamiento de los centros educativos. El efecto aparentemente "paradójico" de estas reformas es que permitieron a los gobiernos centrales adquirir un control todavía mayor sobre la vida diaria de las instituciones escolares. Eso fue debido a la forma en que el proceso de descentralización se llevó a cabo: sin la asignación de los recursos necesarios. En la actualidad, tras casi treinta años de unas reformas que pretendían aumentar la autonomía educativa, las administraciones centrales han aumentado su poder a la hora de determinar las políticas escolares, los currículums y el proceso de evaluación. Incluso han creado instituciones dotadas con los medios para ejercitar un control más estrecho sobre el rendimiento de las escuelas. Lo más grave es que, ahora, quienes determinan el funcionamiento de los centros educativos no son los principios ni las necesidades educativas sino los objetivos de los programas financieros de ajuste económico o programas de ajuste estructural (Fischman y Gandin, 2008).

Ya no se trata de luchar por una mejora de la educación y el sistema educativo, de procurar más recursos donde más se necesiten, de dar más apoyos a aquellos centros con más dificultades, sino que se fomenta la autonomía como forma de competencia entre centros educativos. Competencia que se ve acrecentada y potenciada por una política de exigencia de 
resultados. Unos en los que se concentra toda la población minoritaria o con necesidades, que están en zonas periféricas o rurales, con escasos recursos y profesorado interino lo cual impide la consolidación de un equipo estable, frente a otros que concentran a la población de clase media y alta, con muchos recursos. De esta forma aumentará aún más la brecha social que ya existe actualmente, consolidando la polarización social y destruyendo la igualdad de oportunidades y la cohesión social (Cañadell, 2015).

Esta competencia entre centros, auspiciada por las administraciones educativas con la publicación de estos rankings, potencia mecanismos de mercado donde las escuelas luchan para mostrarse o venderse como 'mejores' que las otras, para resaltar su supuesto "valor añadido", sea en términos de proyectos de bilingüismo o emprendimiento, instalaciones y recursos, resultados académicos, modelos disciplinarios, "innovaciones", etc. Y las familias Iuchan para acceder a aquellas escuelas que aparecen en este mercado de oportunidades como las "mejores", las que están en los puestos superiores de los rankings. "Porque efectivamente las familias (sobre todo aquellas con más capital cultural) saben que no escogen entre escuelas diferentes sino entre escuelas eminentemente desiguales. Desiguales en oportunidades y condiciones para el aprendizaje y el desarrollo integral de sus hijos e hijas. Y ahí es donde radica la trampa de numerosos discursos. En tratar como sinónimos 'diferencia' y 'desigualdad'” (Tarabini, 2017). Unas escuelas son gratuitas y otras cobran cuotas que dificulta el acceso a determinados sectores sociales; porque unas concentran toda la diversidad de alumnado que llega durante el curso por cuestiones migratorias y otras tienen un alumnado prácticamente "idéntico" durante toda la etapa escolar; porque unas tienen pantallas digitales en todas las aulas y otras no tienen ni ordenadores; porque unas tienen un profesorado estable, mientras otras tienen una plantilla docente que no deja de cambiar año tras año. Por eso, como explica esta especialista, los discursos que enfatizan las virtudes de la competencia entre centros, la autonomía para reforzar la especificidad y, por tanto, la diferencia entre centros y la "libre selección" de centro educativo olvidan que la educación es un bien común y un derecho que hemos de garantizar a todos los niños y niñas en condiciones de igualdad, no una ventaja competitiva individual que hay que aprovecha en un entorno competitivo.

Además, esta manera de concebir la autonomía y la descentralización supone el traspaso de responsabilidades y funciones, desde la Administración a cada centro y a su comunidad educativa en particular. Una vez establecida este tipo de autonomía, los resultados ya no son responsabilidad del sistema, ni de la Administración, sino del propio centro, o sea, de los docentes que trabajan en él. De hecho, detrás de estos conceptos se esconde una "privatización" encubierta de los centros públicos, en el sentido de que no forman ya parte de un "todo" que es el sistema educativo, sino que cada 
uno se convierte en una entidad individual que debe entrar a competir con los demás y debe además rentabilizar sus recursos (exactamente igual que si fuera una empresa).

Se extienden así los "contratos-programa" entre la Administración y cada centro particular o cada universidad, que individualizan la relación con la Administración y donde ésta condiciona el aumento de la financiación a la presentación de resultados cuantificables. Contratos-programa que se dotan en función de los resultados obtenidos. Esto no sólo desarticula los mecanismos unificados de negociación con los sindicatos de trabajadores y trabajadoras de la educación y flexibiliza las formas de contratación y las retribuciones salariales de los colectivos docentes, sino que exime al Estado de su obligación de suministrar los recursos necesarios y garantizar la calidad del servicio, y permite que la Administración se desentienda progresivamente de la financiación de los centros públicos, especialmente de los que más necesitan apoyo y recursos dejando en manos de los "gestores educativos" la responsabilidad de dar una educación de calidad. De esta forma, la responsabilidad del éxito o fracaso del funcionamiento de los centros se delega en las comunidades educativas (Apple, 2002; Cañadell, 2005, 2016).

Estas estrategias para eludir la responsabilidad de la Administración educativa, a quienes se ha encomendado el diseño, planificación y la gestión de la educación pública, suelen envolverse en el lenguaje de la descentralización administrativa, la apertura a la comunidad, y la participación de los sectores implicados. Sin embargo, al mismo tiempo que se proclama este supuesto proceso de autonomía, esta estrategia se ve compensada por un no menos poderoso proceso centralizador fundado en el desarrollo de programas nacionales de control y evaluaciones estandarizadas de los contenidos educativos (básicamente, pruebas de rendimiento aplicadas a la población estudiantil); el diseño centralizado de reformas curriculares que establecen los contenidos básicos de un "currículum nacional"; y, la implementación de programas nacionales de formación de profesorado que permitan la actualización de los docentes según el plan curricular establecido en la citada reforma centrados en esos mismos contenidos (emprendimiento, bilingüismo, TIC, etc.).

En suma, la salida que el neoliberalismo encuentra a la crisis educativa es producto de la combinación de una doble lógica centralizadora y descentralizadora: centralización del control pedagógico a nivel curricular en los contenidos establecidos a nivel central, a nivel de la evaluación estandarizada del sistema y a nivel de formación de los docentes (Medeiros, 2015); y descentralización de los mecanismos de financiamiento del sistema. 


\section{Una gestión democrática y participativa}

Debemos abandonar la demanda neoliberal de soluciones tecnocráticas a los problemas educativos y asumir que, por encima de todo, la educación es una cuestión política y democrática y también de valores. Tenemos que cuestionar la lógica economicista de la competitividad que domina el lenguaje político de la educación de la Unión Europea, el Banco Mundial, la OCDE y la UNESCO, articulado a través de sus muchos y repetitivos "textos persuasivos" que subordinan la política educativa a las demandas de flexibilidad del mercado de trabajo y/o la empleabilidad y los imperativos percibidos de la competitividad.

Para ello hay que trabajar en los tres niveles de participación, el comunitario (lo que respecta al contexto del centro), el político (la gestión del centro) y el académico (referido al proceso de enseñanza y aprendizaje). En el comunitario es necesario revisar y llevar a la práctica concepciones que van pasando de moda sin ni siquiera haber hecho mella en la mayoría de los centros educativos: la ciudad educadora, el aula sin muros, la escuela abierta, la comunidad educativa, etcétera.

Respecto a nivel de centro, se puede concretar la participación en todos los elementos organizativos mediante la democratización del uso de los espacios, compartiendo los tiempos, dinamizando la comunicación, diseñando, realizando y evaluando experiencias compartidas, etc. Pero es posible seguir avanzando en la profundización de la democracia con proyectos e ideas que potencien la participación real de todos en la gestión de los centros educativos: rotación de cargos directivos o estructuración de cargos directivos colegiados y paritarios; impulsar los presupuestos participativos en el centro, de tal forma que faciliten la corresponsabilidad de toda la comunidad educativa en definir prioridades y decidir la distribución de los recursos públicos en función de sus necesidades y urgencias, que deben ser establecidas por el Consejo Escolar; etc.

Todo esto implica: 1) Promover el asociacionismo y la participación democrática de toda la comunidad educativa en la gestión de los centros, en particular del alumnado y de padres y madres, que facilite la cogestión del centro. 2) Reconocer los derechos del movimiento asociativo de las AMPAS y las asociaciones de estudiantes, impulsando y regulando la obligación que tienen las administraciones educativas para financiarlas y apoyar su funcionamiento y participación en el sistema educativo. 3) Hacer efectiva la corresponsabilidad del profesorado y las familias en la educación, con apoyo de las administraciones. 4) Ampliar las competencias en educación de los ayuntamientos, para la organización y funcionamiento de determinados servicios y actividades de forma coordinada. 
Una visión amplia de la participación y gestión ciudadana en educación implica que el barrio, el pueblo, las instituciones, etc. forman parte del proceso educativo y se deben abrir canales de participación ciudadana en ellas y del centro en los espacios sociales.

\section{Bibliografía}

Apple, M. (2002). Educar "como Dios manda". Mercados, niveles, religión y desigualdad. Barcelona: Paidós.

Aróstegui, J.L. Y Martínez, J.B. (Coords.) (2008). Globalización, posmodernidad y educación: la calidad como coartada neoliberal. Madrid: Akal.

Ball, S.J. (2003). The teacher's soul and the terrors of performativity. Journal of Education Policy, 18(2), 215-228.

Ball, S. J. (2016). Gobernanza neoliberal y democracia patológica. En J. Collet y A. Tort. (Coord.). La Gobernanza Escolar (pp. 23-40). Madrid: Morata.

Ball, S.J. y Youdell, D. (2007). Privatización encubierta en la educación. Bruselas: Education International.

Bautista, J. (Coord.). (2012). Innovación en la universidad. Prácticas, políticas y retóricas. Barcelona: Graó.

Bernal, J.L. y Lacruz, J.L. (2012). La privatización de la educación pública. Una tendencia en España. Un camino encubierto hacia la desigualdad. Profesorado. Revista de currículum y formación del profesorado, 16(3), 81-109.

Bernal, J.L. y Vázquez, S. (2013). la nueva gestión pública (NGP/NPM): el desembarco de las ideas neoliberales con la LOMCE. Tempora, 16, 35-8.

Bolívar, A. (1999). Crítica de la calidad total. Aula de Innovación Educativa, 83, 78-82.

Bolívar, A. (2010). El liderazgo educativo y su papel en la mejora: Una revisión actual de sus posibilidades y limitaciones. Psicoperspectivas, 9(2), 9-33.

Bolívar, A. (2013). Cambio y liderazgo educativo en tiempos de crisis. Organización y gestión educativa: Revista del Fórum Europeo de Administradores de la Educación, 21(4), 14-17.

Bolívar, A., López, J. y Murillo, J. (2013). Liderazgo en las instituciones educativas. Una revisión de líneas de investigación. Fuentes, 14, 15-60.

Cañadell, R. (2005). El debate oculto sobre la educación. Cuadernos de Pedagogía, 346, 82-86.

Cañadell, R. (2015). De la protesta a la propuesta: Una ILP para un nuevo sistema educativo en Cataluña. El Viejo topo, 326, 48-55.

Cañadell, R. (2016). La lucha educa. Movimientos sociales y renovación pedagógica: Educación, lucha y transformación social. Viento sur: Por una izquierda alternativa, 147, 47-55.

Chiva, R. (2017). La gestión de la calidad o cómo acabar con la Universidad lentamente. El Diario.es. Recuperado de https://goo.gl/t5AJkQ] 
Colella, L. y Díaz, R. (2017). Análisis de la calidad educativa en el discurso neoliberal. Educar, $53,2,447-465$.

Collet, J. y Tort, A. (Coord.). (2016). La Gobernanza Escolar. Madrid: Morata.

Díez, E.J. y Guamán, A. (Coords.) (2013). Educación pública: de tod@s para tod@s. Las claves de la "marea verde". Madrid: Bomarzo.

Fernández-González, N. (2016). Repensando las políticas de privatización en educación: El cercamiento de la escuela. Archivos Analíticos de Políticas Educativas, 24(123), 36-44.

Fischman, G.E. y Gandin, L.A. (2008). Escola Cidada y los discursos críticos de esperanza educativa. En P. McLaren y J.L. Kincheloe (Eds.). Pedagogía crítica. De qué hablamos, dónde estamos (pp. 287-304). Barcelona: Graó.

Foucault, M. (1975). Vigilar y Castigar. México: Ediciones Siglo XXI.

García, M. (2016). Dirección pedagógica y liderazgo educativo: prácticas eficaces en centros públicos andaluces. Tesis doctoral. Granada: Universidad de Granada.

Gentili, P. (1997). Cultura, política y currículo. Ensayos sobre la crisis de la escuela pública. Buenos Aires: Losada.

González, M.T. (2017). La dirección del centro escolar y el liderazgo pedagógico. Revista Padres y Maestros, 370, 6-11.

Medeiros, SH.D. (2015). Políticas de formación docente para la educación profesional: oposiciones y permanencias marcados por el ideario neoliberal. Acta Scientiarum. Education, $37(2), 165-175$

Moreno-Hidalgo, M. y Manso, J. (2017). La Nueva Gestión de lo Público (NGP) como tendencia educativa global y su impacto en la conformación de la identidad docente. RIESED Revista Internacional de Estudios sobre Sistemas Educativo, 2(7), 33-51.

Moya, J. (2014). La ideología del esfuerzo. Madrid: Catarata.

Navarro, M.A., Guzmán Ibarra, I. y Guaderrama Martínez, X.R. (2016). Una mirada sobre la dirección escolar. En José Luis Bernal Agudo (Coord). Globalización y organizaciones educativas: Comunicaciones (pp. 323-330), Zaragoza: CIOIE.

Quiroga, A. R. (2017). Escuela y producción de subjetividad. El papel de la educación en las sociedades del gerenciamiento y el paradigma de la gestión escolar. Ixtli. Revista Latinoamericana de Filosofía de la Educación, 4(8), 221 - 235.

Ritzer, G. (1993). The McDonaldization of Society: An Investigation into the Changing Character of Contemporary Social Life. Newbury Park, CA: Pine Forge Press.

Saura, G. (2017). ¿Crisis? ¿Qué crisis? Filantrocapitalismo, neoliberalización y gobernanza en la política educativa global. Nuestra Bandera, 236, 32-43.

Saura, G. y Muñoz, J.L. (2016). Prácticas neoliberales de endo-privatización y nuevas formas de resistencia colectiva en el contexto de la política educativa española. Revista Educación, Política y Sociedad, 1(2), 43-72.

Sebastián, E, Catalán, J.P., Herrera, F., Utrera, C., Acosta, J.S. y Martín, M. (2016). El liderazgo en la dirección y gestión para instituciones educativas en España e Iberoamérica. En José Luis Bernal Agudo (Coord). Globalización y organizaciones educativas: Libro de Simposios (pp. 70-103), Zaragoza: CIOIE. 
Tarabini, A. (2017). De nuevo con la elección escolar: o cuando la diferencia se confunde con la desigualdad. El diario de la Educación. Recuperado de https://goo.gl/909bTq

Vargas Jiménez, I. (2017). Mirada de la comunidad educativa acerca del desempeño de directivas educativas: Algunas reflexiones. Revista Electrónica Educare, 21(1), 1-7.

Verger, A. y Bonal, X. (2012). La emergencia de las alianzas público-privado en la agenda educativa global: nuevos retos para la investigación educativa. Profesorado. Revista de currículum y formación del profesorado, 16(3), 11-29.

Verger, A.; Bonal, X. y Zancajo, A. (2016). Recontextualización de políticas y (cuasi)mercados educativos. Un análisis de las dinámicas de demanda y oferta escolar en Chile. Archivos Analíticos de Políticas Educativas, 24(27), 42-54.

Viñao, A. (2016). El modelo neoconservador de gobernanza escolar: Principios, estrategias y consecuencias en España. En J. Collet y A. Tort. (Coord.). La Gobernanza Escolar (pp. 41-64). Madrid: Morata. 